\title{
MANAGING KNOWLEDGE WITHIN REGENERATION PRACTICE
}

\author{
JOYCE LIDDLE \\ University of Nottingham
}

\section{Introduction}

There is a vast literature on knowledge management and organisational learning. Few writers disentangle the two, with some regarding them as complementary terms. Approaches to knowledge management are generally located within the arena of practice, whereas organisational learning literature tends to emphasise what is learned by an individual, or learning as a social process, within or between organisations (Gourlay, 2004). Salk and Simonin (quoted by Gourlay) provide a useful review of the literature on alliances and inter-organisational collaboration to propose a broader conceptualisation of knowledge and learning. Plaskoff showed how communities of practice provide potential for both in the world of practice but Easterby-Smith and Lyles (2003) suggest inter-cultural communication has hitherto been a neglected area in this vast literature. The notion that knowledge and learning are the prerogative of a select group of experts or practitioners has shifted to one in which knowledge is distributed through communities of practice (Dixon, 2000), and the sharing of common knowledge is seen as a pre-requisite for growth and success (Lakomski, 2004). Groups of people who share a concern, a set of problems, or a passion about a topic deepen their knowledge and expertise by interacting on an on-going basis (Wenger, 2002).

Knowledge in social sciences is highly contextualised, interactive and collaborative but tied to values, beliefs and goals embedded in those communities in which it is created and used. Therefore using knowledge in such contexts is rarely a simple matter of transfer or dissemination of neutral information, but raises questions of ethics, empowerment, and sensitivity to local practices. Knowledge within regeneration practice is dynamic and social, as well as being held by key individuals. It can be tacit or explicit and generated in collaboration with others in specific tasks. Tacit knowledge as embodied experience has the benefit of allowing dynamic responses to context specific problems. Story telling and narrative, coaching and conversations can facilitate sharing tacit knowledge, but this form of knowledge transfer is at a very early stage of development (Liddle and Smith, 2004). Much of the knowledge generation and distribution in regeneration is socially framed and is an amalgam 
of accumulated experiences, actions, conversations, and the reflections of a variety of stakeholders at different times on different issues.

Within regeneration, greater citizen participation and broader stakeholder engagement in decision-making and problem solving is seen as a good thing, and indeed many recent public sector reforms have at heart the need for increased involvement. Demands for more, better or enhanced citizen participation have arisen because of the apparent limitations of representative democracy and the role of the state as a moderator between social actors and a promoter of societal self-regulation, rather than a Leviathan intervening in society from above (Abels, 2005, p.15). By involving the views and interests of groups usually excluded from the political process, recent reforms, such as those evident in the regeneration of deprived communities, have sought to broaden the cognitive and normative basis, initiate social learning, reduce social conflict, promote public interest and increase the legitimacy of political decisions. Pratchett (2000) argues that representative democracy has been replaced by consultative and deliberative forms of democracy involving broader groups of interests and views. However, broadening decision making to multi-stakeholder groups is not without difficulties, not least the capacity to develop effective decisions, based on appropriate evidence, data and information. Martin (2003) developed a model of co-planning and co-production of service delivery and Figure 1 shows how the general public as well as users of services can achieve active involvement in policy design and delivery of services, which is superior to the traditional one-way flow of information to stakeholder or service users. However, to achieve this co-production and co-planning requires greater use of evidence, data and information than in past practice.

\section{Figure 1}

\section{Communication}

One-way flow of information from service providers to public/users

\section{Consultation}

Two-way dialogue

between service

providers and

public/users

\section{Co-planning and} Co-production Active involvement of public/users in policy design and delivery of services

\section{Adapted from Martin (2003)}

The capacity to achieve structured reflection on policy and management problems is recognised as a crucial ingredient in improved organisational performance and, in the field of regeneration, agency representatives and communities of practice work in collaborative partnerships to identify common problems and seek appropriate solutions. The obsession with learning from good practice, and providing an "evidence-base" to inform future decision- 
making has informed much of the recent literature in both the public and the private sectors. Despite the pernicious influence of Best Practice in most policy arenas, including regeneration, we must bear in mind that it is always, (i) out of date and "past practice", (ii) sanitised, as human beings learn by doing and learn by experimentation and mistakes, so no two experiences will be the same, (iii) context dependent, thus "one size does not always fit all”, (iv) stifles learning \& innovation, and finally, (v) we don't always know what Best Practice is (Liddle and Smith, 2004).

Too often policy makers adopt a "realistic evaluation" approach to developing policies in a muddled or unsystematic manner after an event (Pawson,2001), whereas Stoker and Greasley (2005) advocate a strategy of experimentation. This may take the form of either action research, where policy makers and practitioners diagnose a problem, plan and organise action steps to respond to that problem and then seek to evaluate the effectiveness of the intervention, or of randomised controlled trials to build on design experiments and produce warrantable tests of interventions to judge what works and why.

Rock (2005) suggests that the more applied the research (and evidence) the more mobilised it becomes. For Levesque (2004), a diverse range of partners (including researchers) produces leading edge data, information and knowledge but the true power and full value of the investment of time, energy, and resources can only be derived when combined with action.

In theory, evidence based practice or evidence informed policy can facilitate an understanding of what needs to be done, illustrate how to recognise problems, formulate questions, select appropriate resources and apply requisite knowledge appropriately, but these processes are difficult to achieve because problems are messy, information choices may be severely restricted and consequences unintended. Many of those working in the field of regeneration may not know where to look for information and knowledge, may not trust the information they are provided with (it may be incomplete or collected for a different purpose to the current needs), and unclear about how to connect available evidence/research with current problems. Furthermore, there is no real evidence to suggest that more knowledge or research data necessarily leads to better decision-making, nor does the possession of more sources of knowledge make for increased success or improved performance. It is crucial to understand that access to appropriate knowledge is paramount in decision- making, and it is essential to question how and why certain knowledge and information have been used in certain ways. Added to these fundamental problems, it is important to understand who has used knowledge and information and for the purposes for which has it been used.

Information and evidence to inform practice must be timely, cost effective and responsive, and there is a need to know when to use data, how to use it, and the type of format the information must be presented in for it to be of value. If information and data is too elaborate, too wordy, or in the form of 
jargon it is not understandable to a wider audience. This is true of information collected by state agencies, as much will have been collected for a completely different purpose for current needs and therefore may be of little use to those who need to access it. Regeneration professionals and communities need to have information provided in digestible formats and to know exactly what they need to draw from available data.

There are literally thousands, if not millions, of data sources available for access but seeing through the maze of knowledge and information is difficult. Lots of examples exist where helpful brokerage or exchange mechanisms have been established, and web based materials are more prevalent. However, without requisite training in accessing, retrieving, using, managing and disseminating information its use will be restricted, as the following discussion reveals.

Regeneration: Gathering appropriate knowledge and evidence?

Within the field of regeneration a stakeholder "cocktail" leads to the determination of community needs. However, communities may not be easily identified nor is stakeholder involvement always clearly evident. The stakeholder concept has been part of common parlance for some time but the problems raised by the complex and fragmented institutional arrangements in local governance have increased the appeal of the concept. Stakeholding, as it is now adopted at the local level, stresses social inclusion and active participation as well as balancing rights, responsibilities and communitarianism. It has also been used to explain and reappraise institutional arrangements, but the number and range of stakeholders in regeneration is wide and each one has the potential to influence the future direction of activities. Rhetorically at least, stakeholding is a prescriptive account that celebrates partnership and assumes that each partner has a level playing field in relation to their power and influence. Donaldson and Preston (1995, pp 66-67), distinguishing between the descriptive, instrumental, and normative aspects, suggest that:

'we cannot presume that managers of a service are the only rightful locus of corporate control and governance'

The iterative nature of strategic decision making within regeneration means that decisions are firmly embedded in a particular political and cultural context, so stakeholders continually interpret information from different perspectives and interests, as well as having diverse cultural frames of reference. Stakeholder relationships within this milieu do not take place in a vacuum comprising dyadic ties, nor are they static. Rather the political and cultural milieu creates iterative processes in which dynamic influences affect others. These interactions between multiple influences constitute a 'stakeholder set' in which individuals will be part of networks of differing levels of importance, density and centrality, and where the degree of interactions will change over time and between issues (Rowley in Donaldson and Preston, 1995). All will alter the very delicate 
balance of power and influence within each policy area. New, experimental, modes of governance within these areas combine components of traditional representative democracy with the more recent participatory, responsive and consultative polity (Pratchett, 2000).

The creation of knowledge is better accomplished through interactions between individuals with different knowledge sets than between individuals with similar knowledge sets because the complexity of the environment and the tasks to be achieved requires diverse knowledge sets (Un and Cuevrvo-Cazurra, 2004, p.28). In the world of regeneration practice it may be suggested that managers inhabit perhaps one of the most complex areas of public management. Nowhere else are managers from traditional professional backgrounds thrown together into such a maelstrom of unpredictability, incompleteness and complexity. In this situation they are expected to put to one side a lot of their own existing knowledge, experience and understanding and learn new skills and competences whilst being forced to work with other partners from other professional backgrounds, in the pursuit of commonly agreed objectives. To add to their difficulties, they must also facilitate community and voluntary sector stakeholder engagement, and many of them have little experience of doing this. Bureaucratic mindsets, based on years of professional training and experience, have not prepared them for such facilitative roles.

Decision-making based on stakeholder engagement can be challenged because it is based on the pluralist premise that a multitude of actors with diverse and competing interests can be 'managed' in any given strategic process by assessing, arbitrating and allocating resources, including information. The very fact that the process of stakeholding needs to be managed creates an imbalance between those who are managing and those being managed. It implies a hierarchy and indicates inequality. The pluralist tendency to conceptualise organisations as constellations of competing stakeholders is extremely problematic too, and seen as naïve and utopian by writers such as Froud and Williams et al. They assert that 'stakeholding is a political fantasy that cannot be a plan for getting from exclusion to inclusion (because) it does not confront the structural reality of redistributive conflict between stakeholders' (1996, p.120).

Pluralist explanations of power fail to show the contradictions and the unequal nature of differing interests and assume that power can be observed, measured or negotiated only through democratic means. They fail to recognise the hidden or structural aspects of power, the historical and social forces shaping political action (Lukes, 1974), or the dominant interests that manage meaning (Fulop and Linstead, 1999). Furthermore, the quality of relationships between stakeholders will be constrained to some degree by the roles assigned to each, by contextually specific practices, techniques, procedures and forms of knowledge routinely developed to shape the conduct of others (Fulop and Linstead, 1999). 
Interests and preferences are not always articulated or observable, and there is an assumption that all parties in decision making will be honest, outspoken and will share their preferences and interests. Decision making in regeneration consists of many varied and different relationships. Some of these will be formal whilst others will be more informal, making it almost impossible to show the way in which power and influence is distributed. Observable means of enquiry cannot always determine the many unwritten agendas of individual actors nor the outcomes of decisions shared between them. The strong desire to be cohesive means that rhetoric is often used to lubricate the process.

Stakeholders need power or influence to affect organisational behaviour but each actor or agency is not necessarily at the centre of one universe. Each will form part of other networks of differing importance, and Rowley (in Donaldson and Preston, 1995) suggests that network density (the denser the number of relationships the greater the diffusion of norms and the more effective the communication) means that a focal organisation will have difficulty playing off well informed and well connected stakeholders who can constrain their actions. Centrality (the closeness or level of dependency), and betweenness (the degree of interaction between actors and agencies) also alters the balance of power. As well as acknowledging that there are direct or indirect levels of power and influence in any regeneration activity it is also important to assess the different requirements and expectations of individual stakeholders for information, particularly if such information is shared, and their needs in relation to the needs of other stakeholders. Specific events can either create unity, diversity, alliance or rifts between competing stakeholder groups so it is important that level, nature and frequency of communication and information are understood. The balance of direct and indirect power and interest changes over time, and depends on a specific programme, with some stakeholders becoming more powerful in some circumstances or when certain issues arise on agendas but becoming less powerful at other times. The following section of the paper examines this issue.

\section{Knowledge Management and learning in regeneration practice}

Within the field of regeneration many of the problems faced by agency representatives and communities are so complex that they are at a loss to know where to begin to address them. They need to understand how to lever knowledge into the world of practice, what types of strategies and tools may be needed for accessing knowledge and, more importantly in cash-strapped arenas, it is essential to have cost effective means for information gathering and sharing knowledge.

Agencies who receive financial support and legitimacy from government sources have a stronger power base than others and can work in partnership to bring together tangible resources (finance, staff, premises) and intangible resources (such as knowledge and information). Conflicts over these resources 
are an inevitable aspect of regeneration practice, as partners vie for a larger 'share of the cake'. Decision-making takes place in fuzzy worlds where we attempt to seek order and clarity. Unfortunately we cannot rationalise away paradoxes, chance, luck, errors, subjectivities, accidents and the sheer indeterminacy of life through a prism of a rationality (Grint, 1997). Many of the decisions taken in regeneration are not rationally thought through, moreover they are more akin to muddling through and successive limited comparisons (Lindblom, 1959), groping along and experimentation (Behn, 1988), logical incrementalism (Quinn, 1980), emergent (Mintzberg, 1998) or characterised by contradiction and fragmentation, as actors mutually adjust to each others viewpoints (Simon, Smithburg and Thompson, 1950).

Within regeneration partnerships there are dynamic relationships cutting across inter- and intra-organisational fields and some very loosely coupled networks at various levels of governance. As the strategic and social context and space for collective action is enlarged the potential for ambiguity over issues of accountability, legitimacy and autonomy is increased. The uncertainty of the environment coupled with the lack of mandatory guidance has created a situation in which individuals and agencies adjust to each other in increasingly flexible and innovative ways in order to maintain, enhance and enlarge their power bases, and this includes using all available means to obtain knowledge and information.

The scale of the problems in deprived or run-down areas is so huge that identifying and assessing where problems lie presents the first hurdle to overcome. Many regeneration partnerships had difficulty at the early stages, primarily because they had little guidance from central government as to how they should be configured, what their membership should be or what processes needed to be put in place to achieve collaborative arrangements. Many took months to agree on their key and tangential problems and to determine their priorities. Once problems were identified and prioritised (and some partnerships were fraught with underlying conflict, past histories and ways of doing things which hindered consensus building) actors then needed to acquire appropriate research, knowledge and evidence from available data sources. The (powerful) holders of evidence, in many cases professionals in government or state agencies, were hierarchically positioned to give out only as much information as they saw fit. The traditional 'top-down' nature of decision-making has created levels of power and authority that are difficult to challenge. In the policy field of regeneration central, regional and local officials may speak the language and rhetoric of openness and transparency but in reality, many channels of communication and information sharing remain firmly closed, despite recent attempts to provide information by electronic means. Knowledge brokers retain significant levels of power in determining which information to divulge.

Even if actors within the field of regeneration are able to access relevant and appropriate knowledge and information, there is then the large question of 
the validity of evidence they receive. On countless occasions, government source data has been challenged as spurious. In addition, there are numerous examples where figures have been questioned. As examples, MORI opinion poll researchers produced evidence in 2004 to counter central government claims that large percentages of the population were happy with levels of service provision in education, health and criminal justice. Figures on unemployment, incapacity claimants, and homelessness have been challenged. The target driven nature of Treasury support for deprived areas, based on levels of multiple deprivation, means that local agents must be pragmatic in using state provided information and data.

The big question facing regeneration practitioners is how to gather and search for appropriate evidence and to synthesise and validate a range of competing data. There is an underlying assumption in regeneration, fostered by state agents, that if professionals can arm themselves with as much information, knowledge and evidence as they can (largely by benchmarking their own practice with the practice of similar regeneration partnerships) then good decisions and better performance will ensue. However, the inherently complex nature of the world means that the chances of repeating a regeneration success in an identical way in a different context are unlikely if not impossible. Whilst different regeneration scenarios may appear to be the same at first glance there will be subtle differences and nuances which make it both individual and unique and a fixed, model driven, approach to regeneration is both impractical and dangerous (Liddle and Smith, 2004).

Regeneration practitioners need to attach significance to the creation of symbiotic relationships and inter-connections between available data, information and evidence and the worlds of practice. One problem is that the world of practice does not comprise one homogenous group of professionals and communities but a heterogeneous mess of competing demands and conflicting objectives. Attempts to provide knowledge brokers, co-ordinators and neighbourhood renewal advisors in order to bring together horizontal relationships (between central, regional, local and community) and vertical relationships (between various partnerships via transferring best practice or examples of transfer of knowledge) have limitations. There are limitations of time, the availability and validity of data, costs of collection, the capacity of those collecting the data, as well as many other problems to overcome in the pursuit of appropriate and feasible knowledge and information.

One important way of transferring knowledge and information between state officials in ODPM (Office of Deputy Prime Minister), HM Treasury, or other central government departments, regionally or locally based officials, regeneration professionals and communities is to have a full appreciation of existing horizontal and vertical interactions and the inter-relationships between the various governance levels. However, these are still largely hierarchical in nature and there is no uniformity in the configuration or composition of 
regeneration partnerships. Moreover, each varies in its professional and community input into decision-making. There are particular problems pertaining to each deprived area, meaning that knowledge identification, acquisition and transfer remain problematic. Conceptualisation of problems at the various levels of state activity and at community levels, as well as differing institutional perspectives on problems, means that knowledge generation is in the hands of a small circle of power brokers. Constraints and limitations on decision making are further bound by the personnel involved, the availability of resources, and the way in which issues are framed and introduced on agendas, as well as the explicit or hidden nature of decisions (Lukes, 1974; Bacharah and Baratz, 1962). Tools and techniques are being developed to assist in decision making, such as IT packages to inform policy and decision making (with many examples emanating from both Canadian and UK contexts), but decisions are still largely framed by members of the professions and not by communities, despite valiant efforts to involve broader inputs. Interactions between types of existing knowledge and practice may have the potential to create common understanding as well as common cultures for evaluating performance, but these are essentially still driven by professions. Most regeneration partnerships still embody professionally driven practices on how partnerships should be constituted, what their remits are, who should be involved, what priorities they have (mainly driven by Treasury targets) and, even when partnerships are newly formed and appraised by Government, the processes are often driven by officials using a blueprint for operational assessment. Most business is conducted by bureaucratic means and this still presents barriers to engaging excluded groups.

Most regeneration partnerships are being asked to develop their own performance management frameworks and models of evaluation. In theory these processes are 'bottom-up' but the reality is that they are very much professionally driven and 'top-down'. One might ask the question 'how much bottom up input can regeneration partnerships have?’ when they are funded by HM Treasury through Government Offices and governed by fairly tight targets, and limited guidance.

\section{Applying some existing models of knowledge and learning}

The following discussion draws from selected research to develop a clearer understanding on how knowledge may be created, acquired, absorbed, transferred, mobilised, utilised and managed in regeneration settings. The aim is to show how potential learning might occur but, in examining some of the barriers in this policy field, there is evidence that difficulties persist.

\section{(i) Knowledge Creation and Acquisition}

The creation or acquisition of knowledge is better accomplished through interactions among individuals with different knowledge sets rather than with individuals with similar knowledge sets. An individual might initiate an idea, 
but it must be combined with other knowledge to ensure that it suits the demands of the context (Un and Cuervo-Cazzuro, 2004). Clearly regeneration partnerships largely consist of very broad stakeholder groupings of individual and agency representation, all possessing different and varied knowledge sets. There is also no shortage of new ideas on how to solve the myriad of problems confronting the multi-agencies. However, two large stumbling blocks remain. First, although partnerships are not legally constituted forums (in most cases a local authority remains the responsible and accountable body for resource deployment) the expectations placed upon them to bring about dramatic change are very high. In most cases they do not have a mandate to bring about the change, nor have they the capacity to draw in mainstream budgets from contributing partner organisations to achieve their aims. Second, although they are expected to identify social, economic and environmental problems and seek appropriate solutions there is evidence that, because of the scale of the problems, many simply do not know where to begin. Moreover, many partnerships do not possess the research capacities to know where to look for appropriate data and information to provide the evidence base for decisions. As an example, Local Strategic Partnerships are currently being scrutinised by both Government Offices and by their 'responsible' local authorities. Most are facing difficulties in carrying out 'self assessment' of their activities in an attempt to provide evidence that they constitute an added benefit to existing governmental agencies. Questions are being raised about how much added benefit these new consultative and participative governance forms provide in relation to longer established representative forms of government. Some local government members are feeling excluded from their role as community leader and are therefore beginning to question the legitimacy of such forms. This forces regeneration partnerships to seek knowledge and data to provide the evidence to justify their continuation. Some are beginning to engage academics (including this author) as an external check on their research activities.

\section{(ii) Knowledge absorption or capacity}

In order to develop a 'knowledge system' there needs to be the capacity to promote interactions between the individual components of a system, that is those who embody the tacit and explicit knowledge needed to solve certain problems. Communication patterns and routinised formal and informal connections and inter-dependencies between actors need to be fully understood. Research indicates that there are well-established forms of communication, linkages and routinised interactions and inter-dependencies between actors and agencies on regeneration partnerships, but there is little evidence to suggest that this is improving the knowledge absorption or capacity of partnerships. In some cases there is evidence of knowledge and information overload. Attendance at forums is suffering in some cases due to the fact that partners have identified where problems lie but lack an adequate resource base or guidance on how to 
proceed; many forums have therefore become 'talking shops'. Some of the key players needed to drive the change process, such as non-statutory agencies and economic, business and community interests, are frustrated at the lack of implementation once strategic priorities are identified. Many Local Strategic Partnerships have been operating for well over two years but some are still at the stage of identifying programmes rather than at the implementation stage. Various reasons for this can be postulated. There is no apparent lack of real financial resource but definitely an inability to build the capacities to drive the change process. Gaps in the capacities of all contributing actors have been identified and a review of central documentation reveals countless programmes to facilitate knowledge transfer and learning. Some examples (there are many others) are:

* Learning Curve

* Neighbourhood Advisors

* Developing Local Learning Plans

* Centres of Excellence in Regeneration

* ODPM funding for Capacity Building of LG Officers (examples are Programmes on Leadership, Performance Management and Evaluation)

* The Academy for Sustainable Communities

* BURA

* Regeneration Exchange

Most of the initiatives have been driven by state officials, are at too early a stage in their lifespan to have been evaluated for effectiveness, and are little understood by regeneration practitioners. In the report Learning and skills for Neighbourhood Renewal it was suggested that knowledge, learning, and skills development, are necessary pre-requisites for successful neighbourhood renewal. Much effort, and financial support has been devoted to defining and disseminating 'good practice' for capacity building in partnerships, as these examples illustrate, but there is little evidence to show that they are having the desired effect at the moment, or are likely to do so in the future.

\section{(iii) Knowledge Mobilisation and Utilisation}

These are the actions that build on the philosophical belief that knowledge has greater value when shared and implemented (Levesque, 2004). For Levesque the major components of Knowledge Mobilisation are What? (data and information production), So What? (interpretation, meaning and context) and Now What? (decisions, actions and impacts). Drawing on an OECD Report that identified market failure in data, information and knowledge, because most published academic papers are never exploited, Levesque suggests that the What? and So What? questions can reach action spaces or practitioners by answering the Now What?. In other words, policy making, the creation of programmes, and the improvement of processes and procedures can all enhance both professional practice and the skills base of all stakeholders engaged in 
various action spaces; and to that we might add the world of regeneration practice. Knowledge Mobilisation occurs when users of research work with researchers/academics and policy makers at the beginning so that a common language can be established. This is where trust is built up and relationships established. However this is time consuming, difficult to achieve and is replete with the complexity of power relationships. The correct information depends on community/partnership needs and whether all parties can develop common values and objectives.

\section{(iv) Knowledge Management}

Knowledge Management, Knowledge Mobilisation and Translation are all attempts to systematically and explicitly build, renew and apply data, information, and knowledge for maximum effectiveness. They are ways of capturing collective expertise wherever it is located. Levesque (2004) suggests that it is about 'getting the right knowledge to the right people at the right time so they can make the "best" decision'. However, regeneration practitioners, continually 'satisfice' rather than 'maximise' (Simon, 1950), and it is therefore appropriate to question Levesque's assumption that if the "'best" knowledge can be derived from the right knowledge base, the right people and the right time' then the best decision will ensue. This fails to account for the fact that in any area of public management, including regeneration, professionals and their stakeholders are always dealing with imperfect information, need to take small, incremental steps towards shifting goalposts, be aware of political whims, and work within bounded rationality and partisan mutual adjustment to the views of other stakeholders (Lindblom, 1959). The messy and fussy world of regeneration is the site of vainglorious attempts to seek order and clarity. Unfortunately, as suggested earlier, we cannot rationalise away paradoxes, chance, luck, errors, subjectivities, accidents and the sheer indeterminacy of life through a prism of apparent control and rationality (Grint, 1997: introduction). In decision-making there are countless variables that we cannot rationalise and account for, though Levesque's sentiments that we must strive for perfection are well articulated.

I share Levesque's view that the development of knowledge assets requires the fostering of relationships built on trust and respect and that we must not be too reliant on sophisticated software such as, for example, search and retrieval engines, the internet, intranets, web browsers, content repositories, electronic news and wikis. There is a clear need to bring together stakeholders with common interests so that they can engender innovative solutions, experiment and reframe problems and act as knowledge brokers for solutions. Nurturing relationships is core to the social activities associated with knowledge exchange, but there are many barriers to overcome for this to happen, not least pre-existing 'top down' models of decision making. A culture of sharing and 
knowledge exchange can only work with active, entrepreneurial support from above rather than the rhetoric that currently persists.

\section{(v) Knowledge Dissemination and Transfer}

Knowledge dissemination is uni-directional with no opportunity for an audience to influence the results. If knowledge and information is presented in the form of jargon communities will be incapable of understanding it. Policy makers and academics that have carried out research may be au fait with the language but it is often exclusive and not easily accessed by others. It is limited in application and will remain with policy makers and academics. Knowledge Transfer, on the other hand, is two way and occurs at the end of a process. It is broader than knowledge dissemination but still quite restricted to policy makers and academics. However, stakeholders can inform the larger agenda, and researchers can be mediators between the communities and academics. Knowledge can be, and often is, mistranslated at this point. Moreover there are still many barriers to overcome in disseminating and transferring knowledge, improving learning and developing the skills and capacities of those operating in the policy arena of regeneration.

\section{Conclusion}

This paper has drawn on a selection of the vast, existing literature on knowledge management and learning in order to draw out some important lessons for the ways in which knowledge, learning, and skills development are currently understood in the policy field of regeneration. There are many stakeholders involved in this arena, with differing levels of experience, knowledge and expertise, and it is important to recognise this if an effective analysis is to be carried out. Contradictory concepts such as knowledge management, transfer, acquisition, dissemination, mobilisation, utilisation, and exploitation add to the problems. Furthermore, there are also definitional and operational difficulties in assessing the knowledge absorption capacities of individuals or representatives who contribute to partnership activities.

The discussion is intended to stimulate a broader debate on the subject, because it is felt that current practice has been too focused on urging regeneration practitioners to seek Best Practice and share experiences and knowledge, without a clear understanding of the difficulties such an approach might create. It has been argued that without a clearer understanding of what knowledge, learning and skills development mean in specific regeneration contexts, policy makers and those responsible for influencing the NR agenda will continue to use and adapt inappropriate models to inform practice.

The paper has related current regeneration practice to existing models of knowledge management and learning to highlight some of the potential limitations and difficulties of such practice. It has shown that, for stakeholders to improve their access, usage, transfer and dissemination of knowledge and 
information, other considerations must be taken into account. An underlying theme of the paper is that regeneration partnerships, like all other decisionmaking forums, contain in built inequalities in power relationships. The issue of the balance of power, and who is setting the knowledge agenda, has yet to be fully explored within regeneration.

\section{References}

Abels G (2005), 'Citizen participation and systems effectiveness' The CSD Bulletin, Centre for The Study of Democracy, Summer 2005, Vol. 12, No.2, pp.15-17.

Bacharach P and Baratz M S (1962), 'The two faces of power', American Political Science Review, Vol.56, No. 3, pp.947-50.

Behn R D (1988), 'Management by Groping Along', Journal of Policy Analysis and Management, Vol.7, No.4, p. 643-663.

Dixon N (2000), 'Common Knowledge: How companies thrive by sharing what they know', Harvard Business School Press, p. 240.

Donaldson T and Preston L (1995), 'The stakeholder theory of the corporation; concepts, evidence and implications', Academy of Management Review, Vol.20.No.1, pp. 65-91.

Easterby-Smith M and Lyles M (2003), The Blackwell Handbook of Organisational Learning and Knowledge Management, Oxford: Blackwell.

Froud J, Haslam C, Suckdev J, Shaoul J and Williams K (1996), 'Stakeholder Economy? From Utility Privatisation to New Labour', Capital and Class, Vol. 60, Autumn, pp. 119-134.

Fulop L and Linstead S (1999), Management - A Critical Text, Basingstoke, Macmillan.

Grint K (1997), Fuzzy Management Contemporary Ideas and Practices at work, Oxford: Oxford University Press.

Grint K(ed) (1997), Leadership: Classical, Contemporary and Critical Approaches, Oxford: Oxford University Press.

Gourlay S (2004), 'On Organisational Learning and Knowledge Management', British Journal of Management, Vol. 15, pp. S96-S99.

Lakomski G (2004), 'On Knowing In Context', British Journal of Management, Vol. 15, pp. S89-S95.

Levesque P N (2004), ‘Knowledge mobilisation-action orientation'. http://homepage.mac.com/peterlevesque/iblog

Liddle J and Smith S (2004), 'Evaluating, or disconnecting the disenfranchised from those who would enfranchise them?', 5th Regeneration Management Research Workshop, University of Liverpool, 18th June.

Lindblom C E (1959), 'The Science of Muddling Through', Public Administration Review, Vol. 19, No. 2, pp. 81-86.

Lukes S (1974), Power, a radical view, Surbiton, Surrey: The Anchor Press. 
Martin S (2003), 'Engaging with citizens and other stakeholders' in Bovaird T and Loeffler E Public Management and Governance, London: Routledge.

Mintzberg H, Ahlstrand B and Lampel J (1998), Strategy Safari. A Guided Tour through the wilds of Strategic Management, Hemel Hempstead: Prentice Hall Europe.

Mori Social Research, Ben Page (Director) (2004), So is the Government delivering?, CIPFA Presentation.

Neighbourhood Renewal Unit (2002), Sharing skills and knowledge to deliver better neighbourhoods, ODPM.

Pawson, R (2001), Evidence-Based Policy: 11. The Promise of 'Realist Synthesis'. ESRC UK Centre for Evidence Based policy and Practice, Queen Mary, University of London

Plaskoff, quoted by Gourlay S (2004), 'On Organisational Learning and Knowledge Management', British Journal of Management, Vol. 15, pp S96-S99.

Pratchett L (Ed) (2000), Renewing Local Democracy? The Modernisation Agenda in British Local Government, London: Frank Cass and Company Ltd.

Quinn J B (1980), Strategies for Change: Logical Incrementalism, Homewood IL: Richard D Irwin.

Rock D (2005), 'Four Types of Knowledge Movement', at http://homepage.mac.com/peterlevesque/iblog

Rowley, in Donaldson T and Preston L (1995), 'The stakeholder theory of the corporation; concepts, evidence and implications', Academy of Management Review, Vol. 20, No. 1, pp. 65-91

Salk and Simonin, quoted in Gourlay S (2004), 'On Organisational Learning and Knowledge Management', British Journal of Management, Vol. 15, pp S96-S99.

Simon H A, Smithburg D W and Thompson V A (1950), Public Administration, New York: Knopf

Stoker G and Greasley S (2005), 'The case for an experimental approach to the applied social sciences: an illustration from the area of civil renewal policy' (unpublished paper).

Un C A and Cuervo-Cazzuro A (2004), 'Strategies for Knowledge Creation in Firms’, Journal of Management Studies, Vol. 15, pp. S27-S41

Wenger E R, McDermott, W M Snyder (2002), Cultivating Communities of Practice: A guide to managing knowledge, Harvard Business School Press. 